\title{
Static and dynamic effective stress coefficient of chalk
}

\author{
Alam, M. Monzurul; Fabricius, Ida Lykke; Christensen, Helle Foged
}

Published in:

Geophysics

Link to article, DOI:

10.1190/GEO2010-0414.1

Publication date:

2012

Document Version

Early version, also known as pre-print

Link back to DTU Orbit

Citation (APA):

Alam, M. M., Fabricius, I. L., \& Christensen, H. F. (2012). Static and dynamic effective stress coefficient of chalk. Geophysics, 77(2), L1-L11. https://doi.org/10.1190/GEO2010-0414.1

\section{General rights}

Copyright and moral rights for the publications made accessible in the public portal are retained by the authors and/or other copyright owners and it is a condition of accessing publications that users recognise and abide by the legal requirements associated with these rights.

- Users may download and print one copy of any publication from the public portal for the purpose of private study or research.

- You may not further distribute the material or use it for any profit-making activity or commercial gain

- You may freely distribute the URL identifying the publication in the public portal

If you believe that this document breaches copyright please contact us providing details, and we will remove access to the work immediately and investigate your claim 


\title{
Static and dynamic effective stress coefficient of chalk
}

\author{
M. Monzurul Alam¹, Ida Lykke Fabricius ${ }^{1}$, and Helle Foged Christensen ${ }^{2}$
}

\begin{abstract}
Deformation of a hydrocarbon reservoir can ideally be used to estimate the effective stress acting on it. The effective stress in the subsurface is the difference between the stress due to the weight of the sediment and a fraction (effective stress coefficient) of the pore pressure. The effective stress coefficient is thus relevant for studying reservoir deformation and for evaluating 4D seismic for the correct pore pressure prediction. The static effective stress coefficient $n$ is estimated from mechanical tests and is highly relevant for effective stress prediction because it is directly related to mechanical strain in the elastic stress regime. The corresponding dynamic effective stress coefficient $\alpha$ is easy to estimate from density and velocity of acoustic (elastic) waves. We studied $n$ and $\alpha$ of chalk from the reservoir zone of the Valhall field, North
\end{abstract}

Sea, and found that $n$ and $\alpha$ vary with differential stress (overburden stress-pore pressure). For Valhall reservoir chalk with $40 \%$ porosity, $\alpha$ ranges between 0.98 and 0.85 and decreases by $10 \%$ if the differential stress is increased by $25 \mathrm{MPa}$. In contrast, for chalk with $15 \%$ porosity from the same reservoir, $\alpha$ ranges between 0.85 and 0.70 and decreases by $5 \%$ due to a similar increase in differential stress. Our data indicate that $\alpha$ measured from sonic velocity data falls in the same range as for $n$, and that $n$ is always below unity. Stress-dependent behavior of $n$ is similar (decrease with increasing differential stress) to that of $\alpha$ during elastic deformation caused by pore pressure buildup, for example, during waterflooding. By contrast, during the increase in differential stress, as in the case of pore pressure depletion due to production, $n$ increases with stress while $\alpha$ decreases.

\section{INTRODUCTION}

The effective stress in a hydrocarbon reservoir typically increases during primary production of oil and gas or may decrease due to waterflooding. In both cases, the effective stress changes as a result of altering the pore fluid pressure. A high porosity and low induration makes the hydrocarbon reservoirs in chalk relatively susceptible to deformation when subjected to increasing effective stress. Compaction in the reservoir and subsidence at the surface may occur due to this deformation. This is a major challenge during production, as exemplified in the North Sea chalk fields (Hermansson and Gudmundsson, 1990; Kristiansen, 1998; Barkved and Kristiansen, 2005).

The Valhall field is a mid-sized (167 million $\mathrm{Sm}^{3}$ ) North Sea oil field at a depth of approximately 2400 meters true vertical depth subsea (TVDSS). The chalk is characterized by high overpressure, undersaturated oil and a high porosity. Typical porosity in this reservoir is $35 \%$ to $50 \%$ and typical matrix permeability is 1 to $10 \mathrm{mD}$, but presence of fractures increases overall permeability (Kristiansen et al., 2005). The exceptionally high porosity was probably preserved in the chalk by early oil emplacement and an overpressure of approximately $20 \mathrm{MPa}$ (Andersen 1995). The stress condition at the beginning of oil production are listed in Table 1. Due to production for more than 20 years, the overpressure has declined to $17 \mathrm{MPa}$ (Tjetland et al., 2007). Consequently, part of the reservoir has compacted and subsidence of the sea floor has reached more than $5 \mathrm{~m}$ and increases by $0.25 \mathrm{~m} /$ year (Kristiansen et al., 2005). Geomechanics modeling related to stress and strain associated with this compaction is required for estimating the stability of wells and platform as well as for the selection of future well locations.

Compaction due to reduction of pore pressure is commonly seen in highly porous chalk reservoirs. Prediction of compaction could

\footnotetext{
Manuscript received by the Editor 21 December 2010; revised manuscript received 1 September 2011; published online 16 February 2012; corrected version published online 22 February 2012.

${ }^{1}$ Technical University of Denmark, Department of Civil Engineering, Lyngby, Denmark. E-mail: mmal@byg.dtu.dk; ilfa@byg.dtu.dk.

${ }^{2}$ Danish Geotechnical Institute (GEO), Lyngby, Denmark. E-mail: hfc@geo.dk.

(c) 2012 Society of Exploration Geophysicists. All rights reserved.
} 
help designing production strategy. If 4D seismic data can be used for the prediction of pore pressure, it is possible to establish a realistic geomechanics model. However, pore pressure should be utilized in a proper way for more accurate compaction prediction.

We study the effect of pore pressure in terms of the effective stress, calculated by using the effective stress coefficient (Biot, 1941). We measure static effective stress coefficient $n$ from mechanical loading tests and compare with dynamic effective stress coefficient, $\alpha$, calculated from elastic wave velocities. We further investigate which effective stress coefficient is relevant for rapid change in pore pressure as in the case of hydrocarbon production.

\section{REVIEW OF THE EFFECTIVE STRESS COEFFICIENT}

\section{Effective stress coefficient}

The effective stress concept was originally introduced by Terzaghi (1923) as the difference between the overburden stress (from the weight of the sediments) $\sigma_{v}$ and pore pressure $P_{p}$. From a rock mechanics view, pore pressure can be seen as working on the internal surface of the rock grains (Engstrøm, 1992). If we, as an example, consider stress in the vertical direction in chalk and focus on a single grain, then the pore pressure can only counteract the overburden stress on the part of the horizontal projection of the grain surface that are in contact with pore fluid. An increase in surface contact between the chalk grains will thus reduce the pore pressure influence on effective stress (Figure 3 of Fabricius, 2010). Biot (1941) characterized this reduction by a coefficient, $\alpha$. The effective stress is then ideally the difference between the total stress $\sigma_{v}$ and a fraction $\alpha$ of the pore pressure $P_{p}$ :

$$
\sigma_{\text {eff }}=\sigma_{v}-\alpha P_{p} .
$$

Terzaghi (1923) studied loose granular sediments, where the contact area among the grain surfaces is negligible and consequently $\alpha$ is close to unity. Therefore, the differential overburden stress $\left(\sigma_{v}-P_{p}\right)$ is equal to the effective stress for these sediments. However, most rocks are cemented to some extent and therefore have more stable grain-to-grain contacts. It makes $\alpha$ less than unity. Due to deformation in a rock mechanics process, there is a possibility of increased or decreased grain contact (softening or hardening behavior). If this happens, the value of $\alpha$ will also change. For this reason, mechanical behavior of a rock should be affected by the changing coefficient $\alpha$.

Biot's (1941) theory was developed on the basis of linear elasticity and reversible strain. Therefore, the coefficient $\alpha$ is typically calculated from the density and velocity of ultrasonic sound wave propagation in dry rocks (Banthia et al., 1965, Todd and Simmons, 1972; Christensen and Wang, 1985; Mavko and Jizba, 1991; Prasad

Table 1. Valhall field stress data (Andersen, 1995). Depth measured from sea surface (total vertical depth subsea or TVDSS).

\begin{tabular}{lccc}
\hline $\begin{array}{l}\text { Depth } \\
\text { (TVDSS) (m) }\end{array}$ & $\begin{array}{c}\text { Pore pressure } \\
(\mathrm{MPa})\end{array}$ & $\begin{array}{c}\text { Hydrostatic } \\
\text { pressure (MPa) }\end{array}$ & $\begin{array}{c}\text { Overburden } \\
\text { stress (MPa) }\end{array}$ \\
\hline 2400 & 44.5 & 25.2 & 48.3 \\
2700 & 46.4 & 28.4 & 54.3 \\
\hline
\end{tabular}

and Manghnani, 1997; Frempong et al., 2007; Mavko and Vanorio, 2010); which produces very small linear elastic strain. We denote it as dynamic effective stress coefficient and use the same symbol $\alpha$ as Biot (1941) because Biot's (1941) derivation is for a purely elastic system, which can only be calculated from dynamic measurements. The coefficient, $\alpha$ is calculated from dry bulk modulus $K_{\text {dry }}$ (modulus of the mineral frame) and bulk modulus of the mineral constituting the frame, $K_{0}$

$$
\alpha=1-\frac{K_{\mathrm{dry}}}{K_{0}} .
$$

For rocks containing practically only one mineral in the frame, $K_{0}$ can be assumed equal to the value for that mineral. For chalk, we assume calcite mineralogy $\left(K_{0}=75 \mathrm{GPa}\right.$; citations in Mavko et al., 2009). $K_{\text {dry }}$ is calculated from the compressional velocity $V_{\mathrm{P}}$ and shear velocity $V_{\mathrm{S}}$ as measured on the dry rock, as well as dry density $\rho_{\text {dry }}$ :

$$
K_{\text {dry }}=\rho_{\text {dry }} V_{\mathrm{P}}^{2}-4 / 3 \rho_{\text {dry }} V_{\mathrm{S}}^{2} .
$$

Based on laboratory measurements of stress dependent sonic velocity, several authors have noted that $\alpha$ is a function of stress (e.g., Banthia et al., 1965; Todd and Simmons, 1972; Christensen and Wang, 1985; Engstrøm, 1992; Frempong et al., 2007) although in the ideal case, $\alpha$ should be constant. Failure to satisfy the assumptions of Biot's (1941) theory, such as constant grain contact area and drainage condition could be reasons for nonconstant dynamic effective stress coefficient.

In a static case, the strain amplitude is higher than in the dynamic case and strain contains elastic and plastic components. Therefore, effective stress coefficient can be different for these two cases. We denote the effective stress coefficient for the static case with $n$.

\section{Earlier studies}

Theoretically the effective stress coefficient is extensively studied (e.g., Geertsma, 1957; Nur and Byerlee, 1971; Todd and Simmons, 1972; Carroll and Katsube, 1983; Mavko and Jizba, 1991; Berryman, 1992; Dvorkin and Nur, 1993; Gurevich, 2004; Ciz et al., 2008). Pressure dependent dynamic effective stress coefficient $\alpha$ is measured by several authors (e.g., Banthia et al., 1965; Todd and Simmons, 1972; Christensen and Wang, 1985; Mavko and Jizba, 1991; Hornby, 1996; Prasad and Manghnani, 1997; Frempong et al., 2007; Mavko and Vanorio, 2010). In addition, Geertsma (1957), Nur and Byerlee (1971), Frempong et al. (2007) as well as Omdal et al. (2009) design experimental setups and conduct mechanical tests to measure the static effective stress coefficient. Although most studies are made on sandstones, Banthia et al. (1965) study Austin chalk, and Omdal et al. (2009) study chalk from the Stevns outcrop in Denmark.

For the 20\% porosity Austin chalk, Banthia et al. (1965) find that the dynamic effective stress coefficient varies from 0.70 to 0.60 in the differential stress range from 3.5 to $14 \mathrm{MPa}$. Omdal et al. (2009) define two different static effective stress coefficients from hydrostatic loading tests; the elastic and the plastic. The elastic effective stress coefficient they determined with an initial effective stress equal to $5 \mathrm{MPa}$ and the plastic effective stress they determined with an initial effective stress equal to $15 \mathrm{MPa}$. For the $>40 \%$ porosity water saturated Stevns chalk, they find that the elastic static effective stress coefficient varies from 0.60 to 0.80 in the differential 
stress range between 0 and $30 \mathrm{MPa}$. The plastic effective stress coefficient for the same chalk ranges between 0.75 and 0.60 in the same stress range. The most important aspect of their finding is the opposite trend of elastic and plastic effective stress coefficients. While the elastic effective stress coefficient increases with increasing effective stress, the plastic effective stress coefficient decreases (Omdal et al., 2009).

Because the effective stress coefficient is described as a bulk property, most of its theoretical formulation and consequently the experimental determination is made under hydrostatic stress conditions (e.g., Nur and Byerlee, 1971; Carroll and Katsube, 1983; Dvorkin and Nur, 1993; Gurevich, 2004; Ciz et al., 2008; Mavko and Vanorio, 2010). However, the stress geometry in the subsurface is most unlikely to be hydrostatic. The first experimental approach of determining the static effective stress coefficient is made by Geertsma (1957). He describes that in a reservoir the prevailing boundary condition is a constant vertical boundary and the absence of rock bulk deformations in the horizontal directions. This indicates that a static effective stress coefficient determined for uniaxial confined stress (uniaxial deformation) conditions will be more relevant in a reservoir compaction study.

\section{Effective stress relevant for rapid change in stress}

Reservoir compaction is monitored by 4D seismic utilizing changes in sonic velocity and changing thickness of layers. To relate this deformation to changes in pore pressure, the effective stress coefficient must be known. So the question is whether we may use $\alpha$ calculated from well $\log$ data to estimate $n$ ? Numerous studies of elastic rock properties, such as Young's modulus, Poisson's ratio, bulk modulus, and shear modulus, show significant difference between static and dynamic elastic properties (Simmons and Brace, 1965; King, 1969; Cheng and Johnston, 1981; Montmayeur and Graves, 1985; Jizba and Nur, 1990; Tutuncu and Sharma, 1992; Tutuncu et al., 1994; Plona and Cook, 1995; Yale et al., 1995; Wang, 2000; Olsen et al., 2008a; Fjær, 2009). Most authors point to microcracks as a major cause of the discrepancy. Other causes include strain amplitude (Simmons and Brace, 1965; Cheng and Johnston, 1981; Plona and Cook, 1995), frequency (Simmons and Brace, 1965; Tutuncu and Sharma, 1992), viscoelasticity (Tutuncu and Sharma, 1992), inelasticity (Cheng and Johnston, 1981; Jizba and Nur, 1990), and stress path (Montmayeur and Graves, 1985; Yale et al., 1995; Fjær, 2009). Plona and Cook (1995) suggest that crack formation at grain contacts during mechanical loading could significantly deviate the static Young's modulus from the dynamic Young's modulus. Olsen et al. (2008a) suggest that the difference in drainage condition between a static and a dynamic experiment is a major source of difference between measured static and dynamic properties. They pointed out that the correct way of comparing dynamic and static Young's modulus for saturated samples is to compare dynamic Young's modulus to the undrained static Young's modulus.

Several authors have found that $\alpha$ may be different for different physical properties. Teufel and Warpinski (1990) find different effective stress coefficients for velocity and for permeability. Berryman (1992) derives a set of effective stress coefficients for different physical properties of rocks, such as porosity, permeability, electrical conductivity, pore volume compressibility, and bulk compressibility. However, the effective stress that is relevant for compaction and subsidence is the effective stress coefficient for strain. This static effective stress coefficient $n$ ideally should be determined from rock mechanics tests designed on the basis of the theoretical definition of Biot (1941).

All these studies suggest that the stress dependence of the static effective stress coefficient $n$ must be established to use 4D seismic data for monitoring reservoir compaction and changes in pore pressure. In addition, an investigation on how this stress dependent $n$ is related to $\alpha$ would allow estimation of $n$ from logging data. If it is possible to establish the relationship between $\alpha$ and $n$, the prediction of pore pressure will become easier and more accurate.

\section{DATA}

Two 1-inch vertical plugs from the reservoir zone of Valhall field, North Sea are investigated for determining the static effective stress coefficient (Table 2). Plugs are cleaned for salt and hydrocarbons by soxhlet extraction. The samples are first refluxed by methanol to remove salts. Methanol is boiled at $110^{\circ} \mathrm{C}$ and the vapor is condensed by flowing water at $12^{\circ} \mathrm{C}$. The absence of measurable chloride is checked by $0.03 \mathrm{M} \mathrm{AgNO}_{3}$ after stopping the process for three days, while the samples in the flask are immersed in methanol. After removing salts, the samples go through toluene refluxing for hydrocarbon removal. Toluene is boiled at $64.5^{\circ} \mathrm{C}$ and the vapor is condensed by flowing water at $12^{\circ} \mathrm{C}$. This process is continued until a clear toluene solution is found after interrupting the process for three days, with the samples immersed in toluene. Cleaned samples are dried in an oven at $55^{\circ} \mathrm{C}$ for two days.

Density as well as stress-dependent dry velocity data for 411.5 inch-diameter vertical core plugs of variable lengths from one vertical well and three deviated wells from the same field are also studied for stress dependency of $\alpha$. Data of these core samples are obtained from the Valhall operators. They were collected at hydrostatic confined stress condition between 2 and $35 \mathrm{MPa}$.

Drying of a sample could have an impact on effective stress coefficient as stiffness of a sedimentary rock can be influenced by the pore fluid (Fabricius et al., 2010). Andreassen and Fabricius (2010) show that failure in a rock occurs at lower stresses if it is saturated with fluids having lower kinematic viscosity. As air has higher kinematic viscosity (approximately $15 \times 10^{-6} \mathrm{~m}^{2} / \mathrm{s}$ ) than brine (approximately $1.2 \times 10^{-6} \mathrm{~m}^{2} / \mathrm{s}$ ), dry (air saturated) rock will behave stronger than brine-saturated rocks. The fluid effect on the strength of rocks can be characterized by Biot's (1956) critical frequency, $f_{c}=(\varphi \eta) /\left(2 \pi \rho_{f l} k\right)$, which is calculated from porosity $(\varphi)$, liquid permeability $(k)$, fluid density $\left(\rho_{f l}\right)$ and viscosity $(\eta)$. The higher the critical frequency, the stronger is the rock (Andreassen and Fabricius, 2010). The effect is more prominent in low-permeability rocks, such as chalk, as fluid flow is strongly affected by the specific

Table 2. Vertical chalk samples from Valhall field; length $(l)$, diameter $(d)$, porosity $(\phi)$, gas permeability $\left(k_{g}\right)$, compressional velocity $\left(V_{\mathrm{P}}\right)$, and shear velocity $\left(V_{\mathrm{S}}\right)$. Velocity is measured at dry condition in the vertical direction applying 3 MPa axial stress.

\begin{tabular}{lccccccc}
\hline $\begin{array}{l}\text { Sample } \\
\text { ID }\end{array}$ & $\begin{array}{c}l \\
(\mathrm{~mm})\end{array}$ & $\begin{array}{c}d \\
(\mathrm{~mm})\end{array}$ & $\begin{array}{c}\phi \\
(\%)\end{array}$ & $\begin{array}{c}k_{g} \\
(\mathrm{mD})\end{array}$ & $\begin{array}{c}\mathrm{CaCO}_{3} \\
(\%)\end{array}$ & $\begin{array}{c}V_{\mathrm{P}} \\
(\mathrm{km} / \mathrm{s})\end{array}$ & $\begin{array}{c}V_{\mathrm{S}} \\
(\mathrm{km} / \mathrm{s})\end{array}$ \\
\hline 6AT4-3 & 13.2 & 24.9 & 32 & 1.1 & 81 & 3.12 & 1.95 \\
6AT4-5 & 18.9 & 24.9 & 40 & 3.5 & 93 & 2.30 & 1.45 \\
\hline
\end{tabular}


surface due to smaller effective pore radius (Fabricius et al., 2010). However, to avoid further complications, we consider air-saturated rocks as dry rocks.

\section{METHODS}

In the present study, we derive $n$ for $1 \mathrm{D}$ deformation from the original definition of Biot (1941). We further set up experiments for determining the stress-dependent static effective stress coefficient $n$ from a $1 \mathrm{D}$ stress condition. In addition, we calculate the dynamic effective stress coefficient $\alpha$ from density and sonic velocities measured on core plugs. We compare $n$ and $\alpha$ for chalks from two porosity groups; $30 \%$ and $40 \%$. We then present a model based on the isoframe model (Fabricius, 2003) to illustrate the relationship between porosity and effective stress coefficient as a function of grain contact cement.

\section{Characterization}

Porosity is determined with a helium porosimeter. Gas permeability $\left(k_{g}\right)$ is measured by flowing nitrogen gas through the samples inside a Hassler-type core holder. The carbonate content in the samples is determined by $\mathrm{HCl}$ dissolution followed by titration with $\mathrm{NaOH}$. The minerals in the rock are determined by X-ray diffraction (XRD). Polished thin sections are prepared from epoxyimpregnated side trims and backscatter-electron (BSE) images are recorded by a JEOL JSM $5900 \mathrm{LV}$ electronic microscope at $1280 \times 960$ pixels resolution on a $42.0 \times 31.5 \mu \mathrm{m}$ area to identify the texture, according to Dunham's classification (Dunham, 1962).

\section{Model based on grain contact cement}

We use the isoframe model (Fabricius, 2003) to quantify the amount of resistance pore fluid can offer against the overburden stress in a cemented rock frame. Isoframe modeling is a mixing procedure that allows the determination of a theoretical modulus, using an upper Hashin-Strikman bound (Hashin and Shtrikman, 1963) for mixing of a solid frame and a suspension. By changing the isoframe value $(I F)$, the theoretical compressional modulus is set equal to the actual compressional modulus derived from compressional velocity data. A higher isoframe value indicates a higher degree of grain-to-grain surface contact due to, e.g., grain contact cementation. This makes the effective stress coefficient lower.

\section{Dynamic effective stress coefficient $\alpha$}

The dynamic effective stress coefficient $\alpha$ is calculated by using equation 2 and equation 3, considering $K_{0}$ as the bulk modulus of pure calcite (Mavko et al., 2009). Sonic velocity is measured by an ultrasonic pulse transmission method in dry samples up to $4 \mathrm{MPa}$ hydrostatic pressure. The pulse is generated in a spike generator and transformed with a set of transducers to P- and S-waves with a center frequency at $0.7 \mathrm{MHz}$. The signal is recorded from an oscilloscope, and velocity is determined from "first break" for the P-wave and "first zero crossing" for the S-wave.

Ideally, sonic measurement should be taken at uniaxial condition (as we did for static measurement). However, due to the limitation of the equipment as well as to be able to compare with a larger data set from the Valhall operator, we use the hydrostatic stress condition for the sonic measurements during our own laboratory tests. Because we use the same sample for static measurement, velocity data is not collected above $4 \mathrm{MPa}$ to avoid damage to the sample. We expect that the stress dependency of the dynamic parameter above $4 \mathrm{MPa}$ is negligible when compared with the static parameter.

\section{Static effective stress coefficient $\boldsymbol{n}$}

During mechanical loading, $n$ is determined based on Biot's (1941) general theory of 3D consolidation. We derive the equation for $n$ under uniaxially confined stress conditions (Appendix A):

$$
n=1-\frac{\left(\frac{\partial e_{a}}{\partial P_{p}}\right)_{\sigma_{d}}}{\left(\frac{\partial e_{a}}{\partial \sigma_{d}}\right)_{P_{p}}}
$$

where $e_{a}$ is the axial strain in a $1 \mathrm{D}$ deformation, $P_{p}$ is the pore pressure and $\sigma_{d}$ is the differential stress.

This equation is in accordance with the theoretical derivation of Todd and Simmons (1972) and as exemplified in the experimental data of Christensen and Wang (1985) for a hydrostatically confined system.

\section{Translation of hydrostatic stress into equivalent uniaxial stress}

Static measurements are done at uniaxially confined stress condition and the dynamic measurements are done at hydrostatic stress condition. In addition, a larger data set obtained from the Valhall operator are measured at hydrostatic condition. Therefore, we calculate equivalent uniaxial stress $\sigma_{a}$ for the hydrostatic measurements by using a translation factor, as explained by Teeuw (1971):

$$
\sigma_{a}=\frac{1}{3}\left(\frac{1+\nu}{1-\nu}\right) \sigma,
$$

where $\sigma$ is the hydrostatic stress. Poisson's ratio $\nu$ is calculated from compressional velocity, $V_{\mathrm{P}}$ and shear velocity, $V_{\mathrm{S}}$ as

$$
\nu=\frac{\left(V_{\mathrm{P}}^{2}-2 V_{\mathrm{S}}^{2}\right)}{2\left(V_{\mathrm{P}}^{2}-V_{\mathrm{S}}^{2}\right)} .
$$

Teeuw's (1971) derivation assumes that the rock is isotropic, and therefore, the horizontal stresses in the reservoir are equal to one another. It also assumes a constant Poisson's ratio. It should be noted that Nieto et al. (1990) claim that Teeuw's assumptions yield horizontal stresses which are only a lower limit. In addition, Andersen (1988) shows that for a North Sea sandstone, Poisson's ratio increases from 0.22 to 0.30 between 0 and $55 \mathrm{MPa}$ hydrostatic stress condition.

\section{EXPERIMENTAL SETUP}

An experimental setup is designed so that the required conditions on which equation 4 is derived can be fulfilled (Figure 1). The setup consists of a thick-walled steel cell so that radial strain may be neglected and strain can be calculated from the axial deformation $e_{a}$ only. Axial stress $\sigma_{a}$ and pore pressure $P_{p}$ are controlled by a valve system so that $\left(\partial e_{a} / \partial P_{p}\right)$ at constant differential stress $\left(\sigma_{a}-P_{p}\right)$ as well as $\left(\partial e_{a} / \partial \sigma_{d}\right)$ at constant pore pressure can be measured. A constant stress rate of $2.78 \mathrm{kPa} / \mathrm{s}(10 \mathrm{MPa} / \mathrm{h})$ is used during loading and unloading. The theoretical strain-stress relationship 
is illustrated in Figure 2. The axial deformation is measured by external high-accuracy linear variable differential transformers (LVDTs) and the load frame positioning system. The axial deformation measured by the load frame is corrected for the systems selfdeflection (virtual infinite stiffness [VIS] correction).

Possible effects from bedding and microcracks are minimized by repeated initial loading to a stress state that closely mimics the in situ conditions of the reservoir rocks. Vertical stress and strain in the reservoir are equivalent to axial stress and strain in the laboratory because the experiments are conducted on vertically oriented core plugs. The axial stress $\sigma_{a}$ and pore pressure $P_{p}$ for the tests were designed to mimic the reservoir stress condition in Valhall field. We use $5 \mathrm{MPa}$ differential stress at the beginning of the test, which represents the initial differential overburden stress condition in Valhall (Table 1). This condition is obtained by applying $50 \mathrm{MPa}$ axial stress and $45 \mathrm{MPa}$ pore pressure. The pore pressure is then reduced to $25 \mathrm{MPa}$, which is equal to the hydrostatic pressure of the Valhall field reservoir zone. This causes the differential stress to increase to $25 \mathrm{MPa}$. It is anticipated that pore pressure could reach this minimum value due to production.

The method is sensitive to a perfect radial contact between the test cell and the sample. If the contact is not perfect, then errors in strain measurements will occur as a result of induced radial strain, such that the true volumetric strain will not be measured from the LVDT reading. Furthermore, the two end surfaces of the sample should be exactly parallel and must fit perfectly with the piston and bottom porous plate. However, by following proper experimental procedure it is possible to overcome these problems.

Core samples are plugged $( \pm 0.05 \mathrm{~mm})$ to match the inside diameter of the cell, so that the sample would fit perfectly (no peripheral flow between the cell and the sample) inside the cell during saturation. Samples are dried at $60^{\circ} \mathrm{C}$ for 48 hours and then placed for 24 hours at ambient temperature before placing them in the test cell. The test cell with the sample is then placed in the load frame and saturated with isopar oil. The volume of the chalk should increase a bit as it sucks oil into the pore space. As axial deformation is restricted by placing the top piston in fixed position the only possible deformation will occur in radial direction. If the sample fits perfectly into the cell, radial deformation will also be restricted and it will show a small increase in pore pressure as it sucks oil during the saturation process. The tests are completed in the following steps (Figure 3).

1) Axial stress $\sigma_{a}$ is increased to $2 \mathrm{MPa}$ keeping the pore pressure, $P_{p}$ at atmospheric.

2) By applying vacuum for 30 minutes, air is sucked out of the system.

3) Saturating under atmospheric pressure for 24 hours with laboratory Isopar-L oil having viscosity $0.00141 \mathrm{~Pa}(1.41 \mathrm{cP})$ and density $0.765 \mathrm{~g} / \mathrm{cm}^{3}$.

4) While keeping $P_{p}=0, \sigma_{a}$ is increased to $9 \mathrm{MPa}$ in an alternating loading-unloading-reloading manner to minimize the bedding effect. No confining stress is applied apart from the walls of the steel cell. The orthogonal component of the axial stress produces strain in radial direction, so that any gap between the test cell and the sample's peripheral surface is eliminated.

5) Test for no peripheral flow at 1,2,4 MPa pore pressure.

6) Axial stress $\sigma_{a}$ and pore pressure $P_{p}$ are increased simultaneously to 25 and $20 \mathrm{MPa}$, respectively.
7) While maintaining at constant differential pressure of $5 \mathrm{MPa}$, $\sigma_{a}$ and $P_{p}$ are increased simultaneously to 50 and $45 \mathrm{MPa}$, respectively. The stress is applied in cycles of $10 \mathrm{MPa}$ loading and $5 \mathrm{MPa}$ unloading to reduce further bedding effect.

8) Pore pressure $P_{p}$ is decreased to $25 \mathrm{MPa}$ at constant $\sigma_{a}$ of $50 \mathrm{MPa}$.

9) While unloading at constant $P_{p}$ of $25 \mathrm{MPa}, \sigma_{a}$ is decreased from 50 to $30 \mathrm{MPa}$.

10) While reloading at constant $P_{p}$ of $25 \mathrm{MPa}, \sigma_{a}$ is increased from 30 to $50 \mathrm{MPa}$.

11) Unloading of pore pressure and $\sigma_{a}$ to atmospheric pressure.

Steps 7, 9, and 10 are used for calculation of $n$ (equation 4, Figure 4). Step 9 and 10 are followed to include the effect on $n$ of waterflooding (axial stress decrease) and oil production (axial stress increase), respectively.

$\left(\partial e_{a} / \partial \sigma_{p}\right)_{\sigma_{d}}$ is calculated from the tangent of the strain-stress curve under loading at constant differential pressure (Figure 4, step 7). Because the deformation is small and the trend is linear, we assume a common tangent from 5 to $25 \mathrm{MPa}$ differential stress (Figure 4).

$\left(\partial e_{a} / \partial \sigma_{d}\right)_{P_{p}}$ is calculated from unloading (Figure 3, 4; step 9) and loading curve under constant pore pressure (25 MPa) (Figure 3, 4; step 10). In this case, tangents are drawn at one $\mathrm{MPa}$ stress intervals because the stress-strain curve is nonlinear under these conditions (Figure 4).

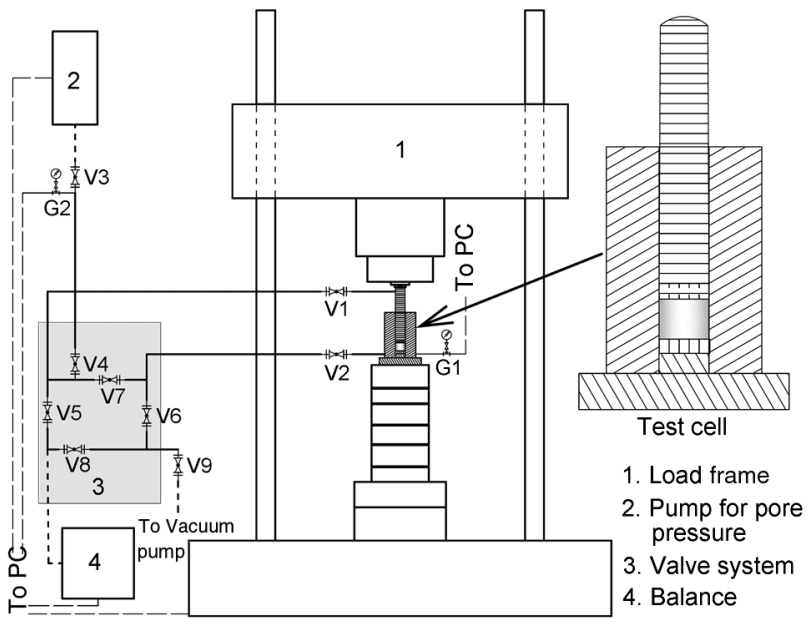

Figure 1. Schematic of the experimental setup for determination of static effective stress coefficient, $n$, using a steel walled compaction rig. $\mathrm{V}$ and $\mathrm{G}$ indicate valves and pressure gauge, respectively.

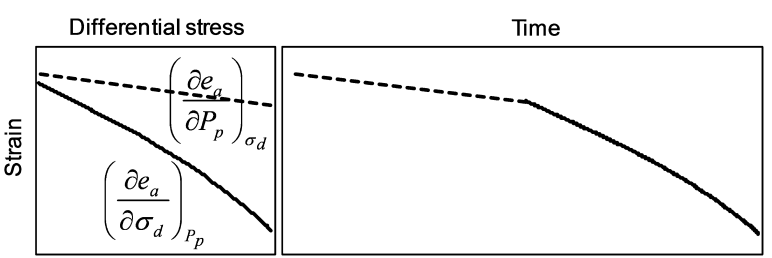

Figure 2. Conceptual strain under stress during loading at constant differential stress, $P_{d}=\left(\sigma_{a}-P_{p}\right)$, and during loading at constant pore pressure, $P_{p}$. The coefficient $n$ was calculated from the slopes of the curves (equation 4). 
a)

Axial stress (MPa)

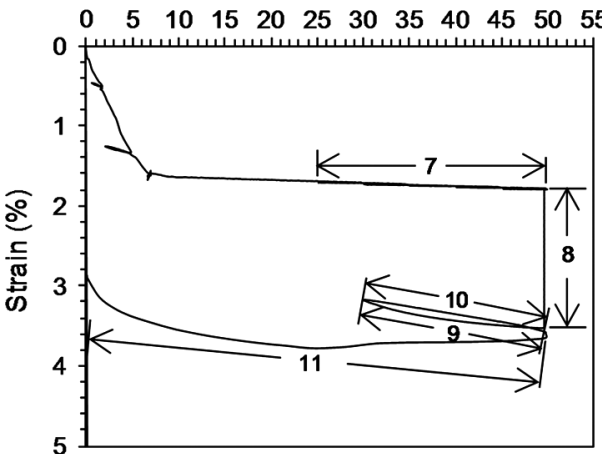

d)

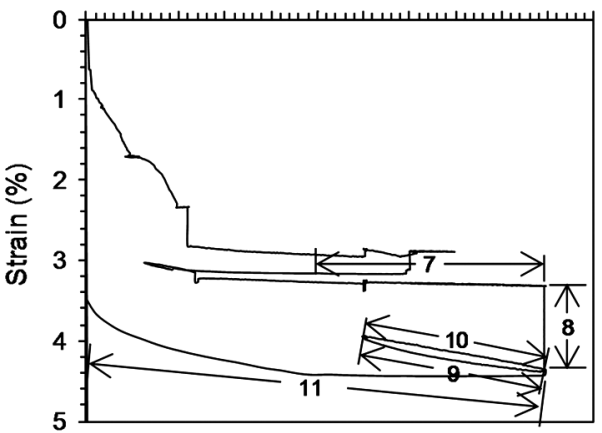

b)

Pore pressure (MPa)

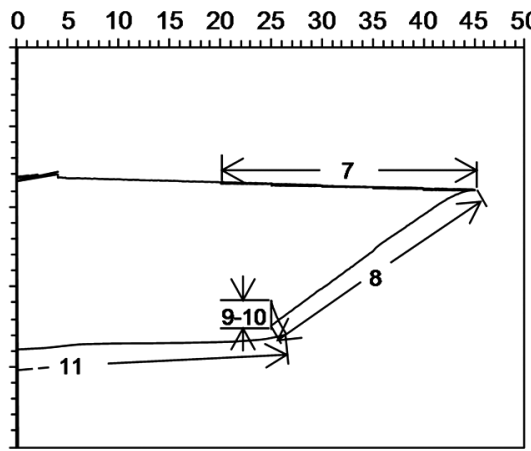

e)

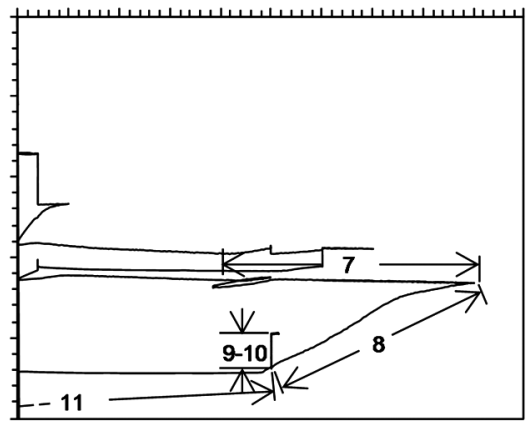

c)

Differential pressure (MPa)

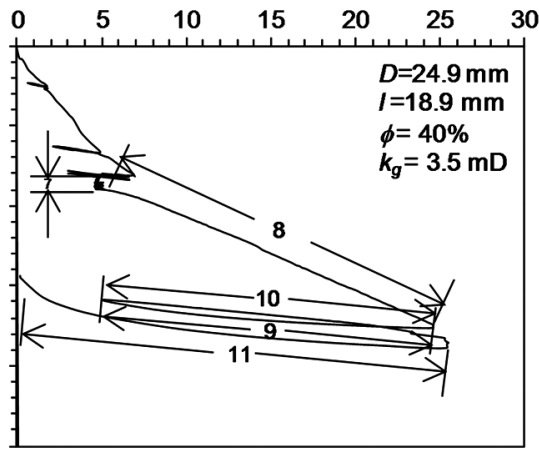

f)

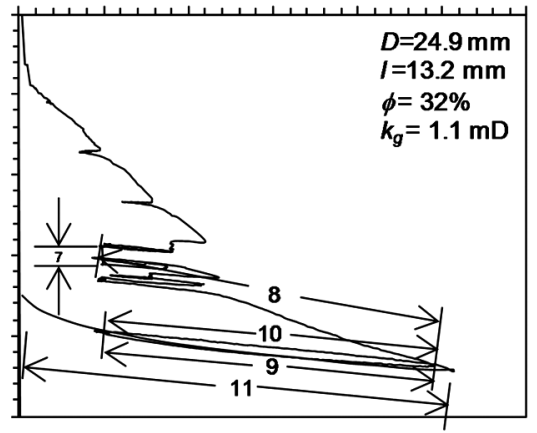

Figure 3. Strain-stress curve produced from the mechanical test as plotted in terms of axial stress, pore pressure, and differential (axial-pore) stress for (a-c) a $40 \%$ porosity and $3.5 \mathrm{mD}$ sample and (d-f) a $32 \%$ porosity and $1.1 \mathrm{mD}$ sample. Steps indicated by number are described in the text.

a)

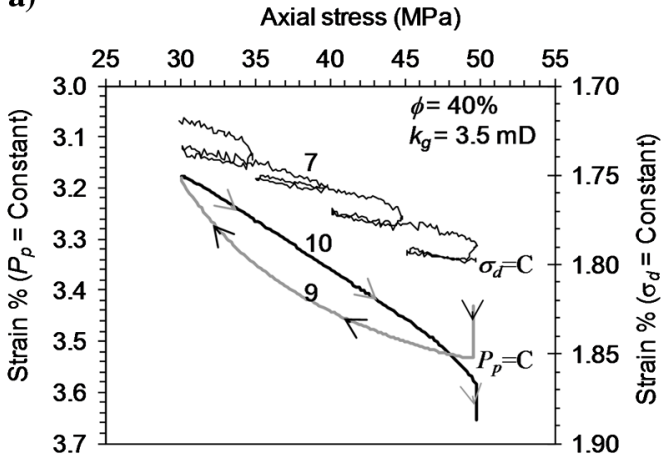

b)

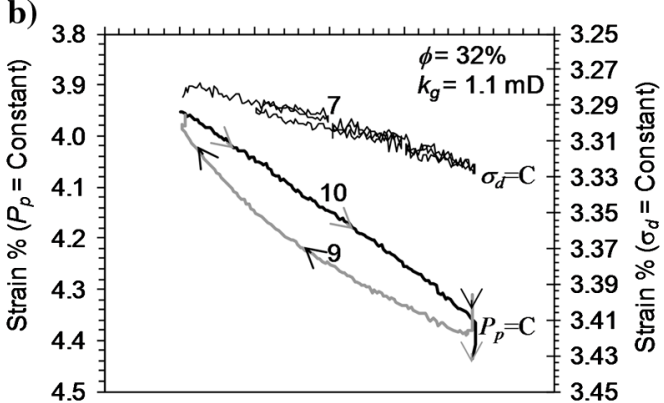

Figure 4. Sections of the curve of Figure 3 used for calculation of $n$. Step 7 is used for the calculation of $\left(\partial e_{a} / \partial \sigma_{d}\right)_{P_{p}}$. Step 9 is used for the calculation of $\left(\partial e_{a} / \partial \sigma_{p}\right)$ for unloading and step 10 for the calculation of $\left(\partial e_{a} / \partial \sigma_{p}\right)_{\sigma_{d}}$ for loading.
The theory used for calculating the static effective stress coefficient assumes that there is no elastic hysteresis. This is only possible if the rock is perfectly elastic, which is rare in nature. To address the change in elasticity, the stress gradient is measured for very small ( $1 \mathrm{MPa}$ ) stress intervals. On this scale, the hysteresis is so small that it can be neglected.

\section{RESULTS}

\section{Characterization}

The two studied samples are notably different in porosity, permeability, and mineralogy (Table 2). Sample 6AT4-3 is used as a representative for $30 \%$ porosity chalk and sample 6AT4-5 is used as a representative for $40 \%$ porosity chalk from the Valhall field. The studied chalk is classified as mudstone according to Dunham (1962) classification (Figure 5). Sample 6AT4-5 has fairly pure calcite mineralogy $\left(93 \% \mathrm{CaCO}_{3}\right)$, whereas, sample 6AT4-3 contains a significant amount of noncarbonate $\left(81 \% \mathrm{CaCO}_{3}\right)$. The noncarbonate fraction in sample 6AT4-3 comprises quartz and kaolinite. Sample 6AT4-5 contains illite in addition to quartz and kaolinite.

\section{Deformation and porosity change in static test}

Both samples deform considerably during the course of the test (Figure 3). Apparently the low-porosity (32\%) sample (6AT4-3) gets more permanent strain $(3.5 \% \approx 0.04 \mathrm{~mm}$, Figure $3 \mathrm{~d})$ than the high-porosity (40\%) sample's (6AT4-5) permanent strain 
$(2.9 \% \approx 0.03 \mathrm{~mm}$, Figure $3 \mathrm{a})$. It may be due to the higher amount of noncarbonate content in sample 6AT4-3. Distribution of the noncarbonate fraction inside the calcite frame may inhibit the growth of grain contact cement between calcite grains, which makes this chalk softer. However, most of the porosity reduction takes place during the application of initial stress applied for removing bedding effect.

The strain obtained during steps 7, 9, and 10, from which static effective stress coefficient is measured is fairly elastic for both samples (Figure 4). During the constant differential stress loading (step 7), sample 6AT4-3 compresses $0.0004 \mathrm{~mm}$ and sample 6AT4-5 compresses $0.0008 \mathrm{~mm}$. Although differential stress is constant during this step, pore pressure increases and samples are strained slightly. If creep can be disregarded during this elastic strain, an increasing effective stress may be inferred, which would indicate a decreasing coefficient $n$ during pore pressure buildup.

During constant pore pressure unloading (step 9), the samples 6AT4-3 and 6AT4-5 rebound by 0.004 and $0.003 \mathrm{~mm}$, respectively. However, loading phase, step 10 , following the unloading phase, step 9, compresses samples 6AT4-3 and 6AT4-5 by 0.004 and $0.004 \mathrm{~mm}$, respectively, when the axial stress increased to $50 \mathrm{MPa}$. It is noted that the amount of deformation during the unloading phase (step 9) and the loading phase (step 10) almost equals out. It indicates that the deformation is reversible and elastic under the applied stress conditions. The elastic strain during steps 9 and 10 corresponds to a $0.2 \%$ and $0.5 \%$ porosity in samples 6 AT4-3 and 6AT4-5, respectively.

\section{Variation of $\alpha$ under stress}

The large sonic velocity data set from the Valhall field shows a significant variation in dynamic effective stress coefficient, $\alpha$, in a broad stress interval (Figure 6). The change in $\alpha$ is larger for highporosity chalk than for lower porosity chalk. For $40 \%$ porosity Valhall chalk the average value of $\alpha$ at atmospheric stress condition is 0.93 , which decreases to 0.88 when $35 \mathrm{MPa}$ hydrostatic stress (20 MPa equivalent uniaxial differential stress) is applied. For $10 \%$ porosity chalk it changes from 0.69 to 0.66 in the same stress range.

\section{Variation of $n$ under stress}

The effective stress coefficient, $n$, varies during a loading or unloading operation (Figure 7). In a mechanical loading cycle, $n$ increases with the increment of differential stress. By contrast, $n$ also increases with the withdrawal of load in an unloading cycle. The low-porosity sample 6AT43 (Figure 7a) shows smaller variation than the high-porosity sample 6AT4-5 (Figure 7b). Upper bound for $n$ for 6AT4-3 is 0.95 , and the upper bound $n$ for sample 6AT4-5 is 0.97 , in the 5to-25-MPa differential stress interval. The lower bound for 6AT4-3 and 6AT4-5 samples are 0.85 and 0.83 , respectively, in the same stress in same stress interval. b)

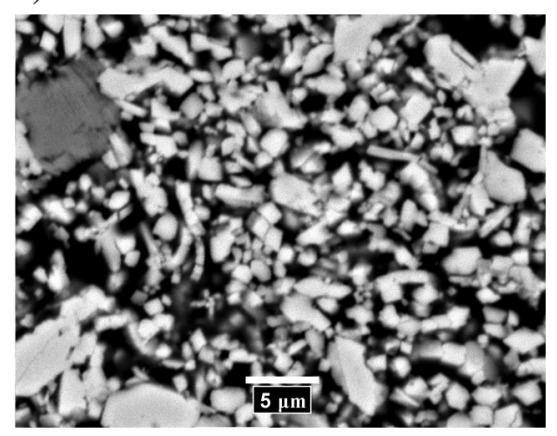

Figure 5. Backscatter electron microscopic (BSE) images of the studied samples (a) 6AT4-3 and (b) 6AT4-5. Black represents pore space. Calcite grains are bright white, while quartz and clay appear as gray.

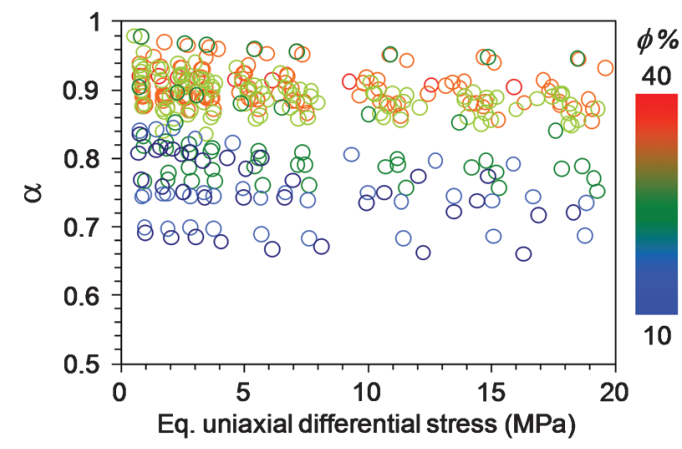

Figure 6. Dynamic effective stress coefficient $\alpha$ calculated from velocity data measured in dry chalk core plugs from Valhall field. Porosity of the samples varies between $10 \%$ and $40 \%$ as indicated by colors. Equivalent uniaxial differential stress for the hydrostatic stress measurement is calculated by equation 5 . The coefficient $\alpha$ shows dependency on the confining stress. For the same porosity, $\alpha$ decreases with increasing stress. Variation of $\alpha$ with stress is higher in the high-porosity samples. The rate of decrease of $\alpha$ decreases for differential stress above $12 \mathrm{MPa}$.

a)

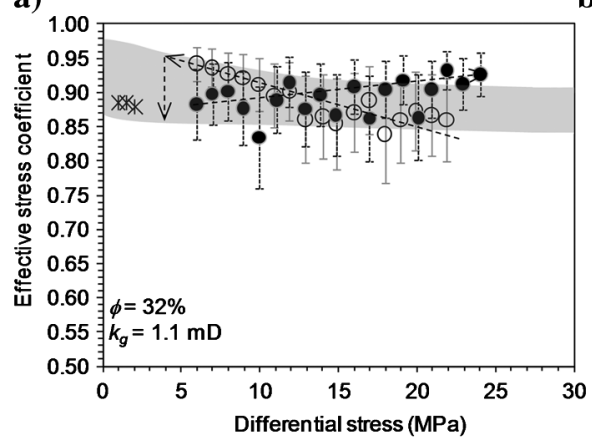

b)

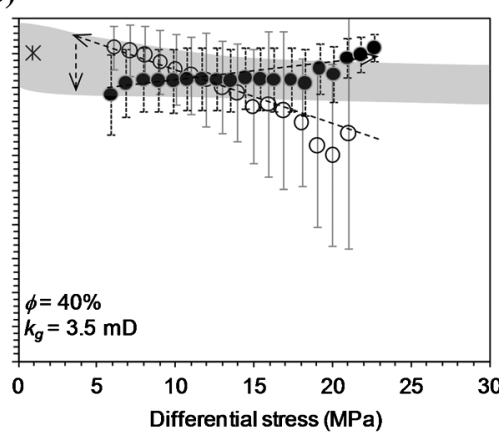

Figure 7. Comparison of $n$ and $\alpha$ of the tested samples. Arrow indicates the order in which data is collected during the loading test. The open circles indicate $n$ calculated from the unloading curve and the solid circles indicate $n$ calculated from loading curve. The dynamic effective stress coefficient $\alpha$ for the same sample is indicated by the stars. Equivalent uniaxial differential stress for the hydrostatic stress measurement is calculated by equation 6 . The shaded region is the expected range of $\alpha$ for respective porosity group (based on data presented in Figure 5). 
The variations with stress of $n$ and $\alpha$ for the studied samples are shown in Figure 7. We made a prediction of stress dependent $\alpha$ for each porosity group from the distribution in the large data set (Figure 6) as indicated by the shaded region in Figure 7.

\section{DISCUSSION}

\section{Behavior of $\alpha$}

The dynamic effective stress coefficient of chalk is in several papers described as a function of porosity only (e.g., Krief et al., 1990; Engstrøm, 1992). However, this kind of relationship may not fully represent the behavior of $\alpha$. Our results indicate that $\alpha$ is not (only) a porosity-dependent coefficient. Laboratory (dynamic) measurements demonstrate that in the range of $20 \mathrm{MPa}$, differential stress $\alpha$ can vary up to $10 \%$ (Figure 6) for high-porosity reservoir chalk from Valhall. This observation is in accordance with Gommesen et al. (2007). They find $\alpha$ as a positive function of porosity with gradient defined by the cementation between grains contacts.

The variation of $\alpha$ can be illustrated by means of effective medium model (Fabricius, 2003). It indicates that it is possible to have a range in $\alpha$ for the same porosity depending on the fraction of mineral in the solid frame (Figure 8). For chalk of constant porosity, $\alpha$ decreases as the cementation increases (Olsen et al., 2008b). The degree of cementation is indicated by the isoframe values (Figure 8). For poorly cemented rocks (low isoframe value), $\alpha$ does not change significantly with porosity and remains close to unity, whereas for strongly cemented rocks, $\alpha$ decreases rapidly with decreasing porosity (Figure 8). The influence of cementation is more significant in the low-porosity chalk. A $20 \%$ porosity chalk may have a $\alpha$ ranging between 0.60 and 0.92 , depending on the cementation, whereas for $40 \%$ porosity chalk, the variation may be less than 0.1 (Figure 8 ). This observation is in accordance with Alam et al. (2010): they show that during the diagenesis process of deep sea carbonate ooze, $\alpha$ does not decrease with porosity unless cementation between the grain contacts starts to develop.

Contact cement precipitation between the grains depends on the diagenetic process of the chalk which in turn impacts on the value of

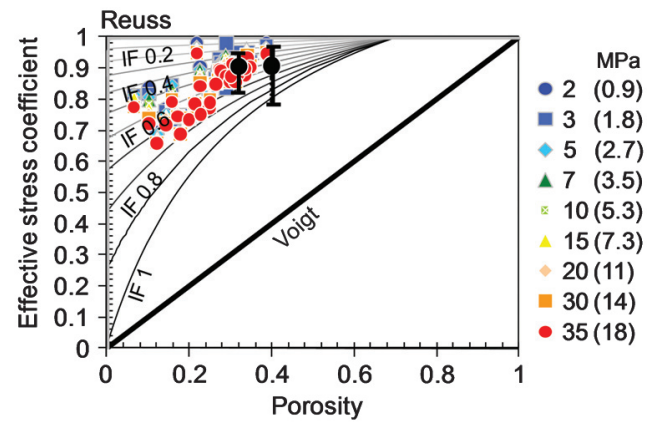

Figure 8. Theoretical bounds for effective stress coefficient together with isoframe curves for a calcite (bulk modulus $75 \mathrm{GPa}$ ) and brine (bulk modulus 2.40 GPa) system. Reuss (1929) gives softest and Voigt (1910) gives stiffest bounds of a fluid-solid system. The coefficient $\alpha$ calculated from core data sorted according to hydrostatic stress of the measurement (as indicated by color code). Equivalent uniaxial differential stress is given in the parenthesis. The effective stress coefficient $n$ calculated from mechanical tests (black circles) shows good agreement with $\alpha$. Variation of $n$ during a static test is indicated by the black bold vertical line through the data point. the effective stress coefficient (Alam et al., 2010). Presence of fine clay may reduce the calcite-to-calcite grain contacts and consequently, the contact cement. This makes the frame weaker and $\alpha$ increases. However, increases in stress may result in elastic deformation of the grains and contact cement and therefore increasing the area of the grain contact. Consequently, the effective stress coefficient decreases.

\section{Behavior of $\boldsymbol{n}$}

Laboratory (static) measurements in this project indicate that $n$ may change more than $10 \%$ for a probably insignificant porosity change of $0.5 \%$ (Figure 7 ).

The test results show that $n$ increases significantly during the unloading cycle. This behavior is similar to that of $\alpha$. During the first part of the unloading of the higher porosity sample, the static effective stress coefficient $n$ has lower value than the possible range of dynamic effective stress coefficient $\alpha$ (Figure 7b). This could be because the unloading cycle is preceded by a rapid decrease in pore pressure (step 8), which would have increased the effective stress and expanded grain contact area. During the unloading process the grains tend to restore their original shape, thus contact area among the grains reduces and $n$ increases. In addition, contact cement between the grains could break during this process as the cement develops during diagenesis when the grains are already strained, so that the cement is strained when the grains are relaxed and vice versa.

There is a sudden drop in $n$ when the direction of stress changes from unloading to loading. It could happen due to the rapid reversal of loading direction. The system could take some time to equilibrate and the stress state to be the same in the entire sample. However, this behavior is not fully understood. The coefficient $n$ increases during the loading cycle (step 10). This behavior is opposite to the trend of $\alpha$, and is unexpected. One possible reason for this increase in $n$ is that the increment of axial stress could break some of the contact cement between the grains (irreversible deformation). This decreases the amount of grain to grain contact. By breaking the contact cement, the fraction of grain in suspension increases and isoframe value decreases (Figure 8). Thus, the load bearing capacity of the solid skeleton decreases and $n$ increases.

\section{CONCLUSION}

The dynamic effective stress coefficient, $\alpha$ as calculated from sonic data is not a constant value for chalk and ranges between 0.80 and 0.95 for the studied samples from the Valhall field. Our mechanical tests indicate that $\alpha$ predicts the static effective stress coefficient, $n$, well for chalk with porosity near $30 \%$, and acceptably for chalk with porosity near $40 \%$. Because it is evident that dynamic and static effective stress coefficients are less than one, the effective stress will always be higher than the differential stress.

For rapid change in stress, it may be more relevant to use the effective stress coefficient $n$ derived from mechanical tests rather than $\alpha$. Our results indicate that for Valhall chalk, $n$ would increase as the reservoir depletes. Our results indicate that $n$ could increase also during waterflooding due to the increase in pore pressure.

In the Valhall field, reservoir compaction and stress history of the rock are monitored by $4 \mathrm{D}$ seismic. The stress induced changes in velocity measured during 4D seismic monitoring include porosity and compressibility alteration. The findings of this project may be 
used to analyze the stress induced mechanical changes in the rocks due to pore pressure changes, which could assist in better understanding of 4D seismic response.

\section{ACKNOWLEDGMENTS}

The financial support from BP Norway and the other Valhall partners (Hess, Shell, and Total) is gratefully acknowledged. The interpretation and conclusions in this paper is the authors and do not necessarily represent the view of the Valhall license. Special thanks to Tron G. Kristiansen of BP Norway for providing data and samples. We thank Kathrine Hedegaard and Frederik P. Ditlevsen of the Danish Geotechnical Institute (GEO) for helping with the experimental setup.

\section{APPENDIX A \\ DERIVATION OF EFFECTIVE STRESS COEFFICIENT UNDER UNIAXIAL STRESS}

Let us consider $\sigma_{x}, \sigma_{y}$, and $\sigma_{z}$ as the normal stress components parallel with the $x, y$, and $z$ coordinate axes, respectively, and the corresponding shear stress component as $\tau_{x}, \tau_{y}$, and $\tau_{z}$. Deformation corresponding to the stress components $\sigma_{x}, \sigma_{y}, \sigma_{z}, \tau_{x}, \tau_{y}$, and $\tau_{z}$ are $e_{x}, e_{y}, e_{z}, \gamma_{x}, \gamma_{y}$, and $\gamma_{z}$, respectively. Additionally, in a rock filled with pore fluid, $\theta$ is the increment in porosity due to an increment in fluid pressure $P_{p}$.

Let us consider a uniaxial system in compression, for which $\sigma_{x}=$ $\sigma_{y}=+\sigma_{r}$ and $\sigma_{z}=+\sigma_{a}$.

According to Terzaghi (1923), pore fluid pressure $P_{p}$ will act in the opposite direction of the principal stresses $\sigma_{x}, \sigma_{y}$, and $\sigma_{z}$, hence, deformation equations as expressed by Biot (1941, equation 2.4) become

$$
\begin{aligned}
& e_{x}=-\frac{\sigma_{x}}{E}+\frac{\nu}{E}\left(\sigma_{y}+\sigma_{z}\right)+\frac{P_{p}}{3 H}, \\
& e_{y}=-\frac{\sigma_{y}}{E}+\frac{\nu}{E}\left(\sigma_{z}+\sigma_{x}\right)+\frac{P_{p}}{3 H}, \\
& e_{z}=-\frac{\sigma_{z}}{E}+\frac{\nu}{E}\left(\sigma_{x}+\sigma_{y}\right)+\frac{P_{p}}{3 H},
\end{aligned}
$$

where $E$ is the Young's Modulus and $H$ is a physical constant defined by Biot (1941) as a measure of the modulus of the rock for a change in pore pressure.

Here, we consider negative sign for compression, which changes the signs of the original derivation of Biot (1941). Biot (1941) made the basic derivation based on tensile forces and described how to use these equations for rocks, in which the stress is compressive, and he changed the sign in Section 3 of his paper (Biot, 1941).

The radial component of the compressive force creates tensile stress in the axial direction. Therefore, the strain component in the axial direction due to the radial stress has opposite (positive) sign of the strain component due to the axial stress (equation A-1).

For uniaxial systems where radial deformation is constrained, we get

$$
e_{x}=e_{y}=e_{r}=0 \text { and } e_{z}=e_{a}
$$

From equation A-1c,

$$
e_{a}=-\frac{\sigma_{a}}{E}+\frac{\nu}{E}\left(\sigma_{r}+\sigma_{r}\right)+\frac{P_{p}}{3 H},
$$

$$
e_{a}=-\frac{\sigma_{a}}{E}+\frac{\nu}{E}\left(2 \sigma_{r}\right)+\frac{P_{p}}{3 H}
$$

From equation A-1a or equation A-1b,

$$
\sigma_{r}=\frac{\nu}{(1-\nu)} \sigma_{a}+\frac{1}{(1-\nu)} \frac{E P_{p}}{3 H} .
$$

Inserting value of $\sigma_{r}$ from equation A-4 in equation A-3,

$$
\begin{gathered}
e_{a}=-\frac{\sigma_{a}}{E}+2 \frac{\nu}{E}\left(\frac{\nu}{(1-\nu)} \sigma_{a}+\frac{1}{(1-\nu)} \frac{E P_{p}}{3 H}\right)+\frac{P_{p}}{3 H}, \\
\sigma_{a}=\frac{E(1-\nu)}{(1+\nu)(1-2 \nu)} e_{a}+\frac{E}{(1-2 \nu)} \frac{P_{p}}{3 H}
\end{gathered}
$$

From the relationship among compressional modulus $M$, Young's modulus $E$, shear modulus $\mu$, and Poisson's ratio $\nu$ :

$$
\begin{gathered}
M=\frac{E(1-\nu)}{(1+\nu)(1-2 v)} \quad \text { and } \\
E=2 \mu(1+\nu) .
\end{gathered}
$$

Hence equation A-5 becomes

$$
\sigma_{a}=M e_{a}+\frac{2(1+\nu)}{3(1-2 \nu)} \frac{\mu}{H} P_{p} .
$$

As defined by Biot (1941), $\frac{2(1+\nu)}{3(1-2 \nu)} \frac{\mu}{H}=\alpha$ is the effective stress coefficient for $3 \mathrm{D}$ consolidation. This would indicate that $\alpha$ is the same for $3 \mathrm{D}$ and confined uniaxial deformation. For uniaxial deformation under static condition, we denote this coefficient as $n$, therefore

$$
\sigma_{a}=M e_{a}+n P_{p}
$$

Differentiating equation A-7 with respect to differential stress when pore pressure is constant

$$
\left(\frac{\partial e_{a}}{\partial \sigma_{d}}\right)_{P_{p}}=\frac{1}{M}
$$

Differentiating equation A-7 with respect to pore pressure when differential stress is constant

$$
\left(\frac{\partial e_{a}}{\partial P_{p}}\right)_{\sigma_{d}}=\frac{1-n}{M}
$$


From equation A-8a and equation A-8b,

$$
n=1-\frac{\left(\frac{\partial e_{a}}{\partial P_{p}}\right)_{\sigma_{d}}}{\left(\frac{\partial e_{a}}{\partial \sigma_{d}}\right)_{P_{p}} .}
$$

\section{REFERENCES}

Alam, M. M., M. K. Borre, I. L. Fabricius, K. Hedegaard, B. Røgen, Z. Hossain, and A. S. Krogsbøll, 2010, Biot's coefficient as an indicator of strength and porosity reduction: Calcareous sediments from Kerguelen Plateau: Journal of Petroleum Science and Engineering, 70, 282-297.

Andersen, M., 1988, Predicting reservoir-condition PV compressibility from hydrostatics stress laboratory data: SPE Reservoir Engineering, 3, 1078-1082, doi: 10.2118/14213-PA.

Andersen, M. A., 1995, Petroleum research in North Sea chalk: RF-Rogaland Research, 174

Andreassen, K. A., and I. L. Fabricius, 2010, Biot critical frequency applied to description of failure and yield of highly porous chalk with different pore fluids: Geophysics, 75, E205-E213, doi: 10.1190/1.3504188.

Banthia, B. S., M. S. King, and I. Fatt, 1965, Ultrasonic shear wave velocities in rocks subjected to simulated overburden pressure and internal pore pressure: Geophysics, 30, 117-121, doi: 10.1190/1.1439526.

Barkved, O. I., and T. Kristiansen, 2005, Seismic time-lapse effects and stress changes: Examples from a compacting reservoir: The Leading Edge, 24, 1244-1248, doi: 10.1190/1.2149636.

Berryman, J. G., 1992, Effective stress for transport properties of inhomogeneous porous rock: Journal of Geophysical Research, 97, 17409-17424, doi: 10.1029/92JB01593.

Biot, M. A., 1941, General theory of three-dimensional consolidation: Journal of Applied Physics, 12, 155-164, doi: 10.1063/1.1712886.

Biot, M. A., 1956, Theory of propagation of elastic waves in a fluidsaturated porous solid. I. Low-frequency range: Journal of the Acoustical Society of America, 28, 168-178, doi: 10.1121/1.1908239.

Carroll, M. M., and N. Katsube, 1983, The role of Terzaghi effective stress in linearly elastic deformation: Journal of Energy Resources Technology, 105, 509-511, doi: 10.1115/1.3230964.

Cheng, C. H., and D. H. Johnston, 1981, Dynamic and static moduli: Geophysical Research Letters, 8, 39-42, doi: 10.1029/GL008i001p00039.

Christensen, N. I., and H. F. Wang, 1985, The influence of pore pressure and confining pressure on dynamic elastic properties of Berea sandstone: Geophysics, 50, 207-213, doi: 10.1190/1.1441910.

Ciz, R., A. F. Siggins, B. Gurevich, and J. Dvorkin, 2008, Influence of microheterogeneity on effective stress law for elastic properties of rocks: Geophysics, 73, no. 1, E7-E14, doi: 10.1190/1.2816667.

Dunham, R. J., 1962, Classification of carbonate rocks according to depositional texture, in W. E. Ham, ed., Classification of carbonate rocks - A symposium: American Association of Petroleum Geologists, 1, 108-121.

Dvorkin, J., and A. Nur, 1993, Dynamic poroelasticity: A unified model with the squirt and the Biot mechanisms: Geophysics, 58, 524-533, doi: $10.1190 / 1.1443435$.

Engstrøm, F., 1992, Rock mechanical properties of Danish North Sea chalk: 4th North Sea Chalk Symposium.

Fabricius, I. L., 2003, How burial diagenesis of chalk sediments controls sonic velocity and porosity: AAPG Bulletin, 87, 1755-1778, doi: $10.1306 / 06230301113$

Fabricius, I. L., 2010, A mechanism for water weakening of elastic moduli and mechanical strength of chalk: 80th Annual International Meeting, SEG, Expanded Abstracts, 2736-2740.

Fabricius, I. L., G. T. Bachle, and G. P. Eberli, 2010, Elastic moduli of dry and water-saturated carbonates: Effect of depositional texture, porosity, and permeability: Geophysics, 75, no. 3, N65-N78, doi: 10.1190/ 1.3374690 .

Fjær, E., 2009, Static and dynamic moduli of a weak sandstone: Geophysics, 74, no. 2, WA103-WA112, doi: 10.1190/1.3052113.

Frempong, P., A. Donald, and S. D. Butt, 2007, The effect of pore pressure depletion and injection cycles on ultrasonic velocity and quality factor in a quartz sandstone: Geophysics, 72, no. 2, E43-E51, doi: 10.1190/ 1.2424887

Geertsma, J., 1957, The effect of fluid pressure decline on volumetric changes of porous rocks: Petroleum Transactions, AIME, 210, 331-340.

Gommesen, L., I. L. Fabricius, T. Mukerji, G. Mavko, and J. M. Pedersen, 2007, Elastic behaviour of North Sea chalk: A well-log study: Geophysical Prospecting, 55, 307-322, doi: 10.1111/gpr.2007.55.issue-3.

Gurevich, B., 2004, A simple derivation of the effective stress coefficient for seismic velocities in porous rocks: Geophysics, 69, 393-397, doi: 10.1190/1.1707058.
Hashin, Z., and S. Shtrikman, 1963, A variational approach to the theory of the elastic behaviour of multiphase materials: Journal of the Mechanics and Physics of Solids, 11, 127-140, doi: 10.1016/00225096(63)90060-7.

Hermansson, L., and J. S. Gudmundsson, 1990, Influence of production on chalk failure in the Valhall field: European Petroleum Conference.

Hornby, B. E., 1996, An experimental investigation of effective stress principles for sedimentary rocks: 66th Annual International Meeting, SEG, Expanded Abstracts, 1707-1710.

Jizba, D., and A. Nur, 1990, Static and dynamic moduli of tight gas sandstones and their relation to formation properties: SPWLA 31st Annual Logging Symposium.

King, M. S., 1969, Static and dynamic elastic moduli of rocks under pressure: Proceedings of the 11th U. S. Rock Mechanics Symposium, 329-351.

Krief, M., J. Garat, J. Stellingwerff, and J. Ventre, 1990, A petrophysical interpretation using the velocities of $\mathrm{P}$ and $\mathrm{S}$ waves (full waveform sonic):: The Log Analyst, 31, 355-369.

Kristiansen, T., 1998, Geomechanical characterization of the overburden above the compacting chalk reservoir at Valhall: SPE/ISRM Rock Mechanics in Petroleum Engineering

Kristiansen, T., O. Barkved, K. Buer, and R. Bakke, 2005, Productioninduced deformations outside the reservoir and their impact on $4 \mathrm{D}$ seisimic: International Petroleum Technology Conference.

Mavko, G., and D. Jizba, 1991, Estimating grain scale fluid effects on velocity dispersion in rocks: Geophysics, 56, 1940-1949, doi: 10.1190/ 1.1443005 .

Mavko, G., T. Mukerji, and J. Dvorkin, 2009, The rock physics handbook: Tools for seismic analysis of porous media, 2nd ed.: Cambridge University Press.

Mavko, G., and T. Vanorio, 2010, The influence of pore fluids and frequency on apparent effective stress behavior of seismic velocities: Geophysics, 75, no. 1, N1-N7, doi: 10.1190/1.3277251.

Montmayeur, H., and R. M. Graves, 1985, Prediction of static elastic/ mechanical properties of consolidated and unconsolidated sands from acoustic measurements: Basic measurements in SPE Annual Technical Conference and Exhibition.

Nieto, J. A., D. P. Yale, and R. J. Evans, 1990, Core compaction correctiona different approach: Advances in core evaluation accuracy and precision in reserves estimation: in F. Paul Worthington, ed.: Advances in Core Evauluation: Accuracy and precision in reserves estimation: Gordon and Breach Science Publishers, 139-158.

Nur, A., and J. D. Byerlee, 1971, An exact effective stress law for elastic deformation of rock with fluids: Journal of Geophysical Research Solid Earth, 76, 6414-6419, doi: 10.1029/JB076i026p06414.

Olsen, C., H. F. Christensen, and I. L. Fabricius, 2008a, Static and dynamic Young's moduli of chalk from the North Sea: Geophysics, 73 , no. 2 , E41-E50, doi: 10.1190/1.2821819.

Olsen, C., K. Hedegaard, I. L. Fabricius, and M. Prasad, 2008b, Prediction of Biot's coefficient from rock-physical modeling of North Sea chalk: Geophysics, 73, no. 2, E89-E96, doi: 10.1190/1.2838158.

Omdal, E., H. Breivik, K. E. Næss, G. G. Ramos, T. G. Kristiansen, R. I. Korsnes, A. Hiort, and M. V. Madland, 2009, Experimental investigation of the effective stress coefficient for various high porosity outcrop chalks: 43rd U.S. Rock Mechanics Symposium and 4th U.S.-Canada Rock Mechanics Symposium.

Plona, T. J., and J. M. Cook, 1995, Effects of stress cycles on static and dynamic Young's moduli in Castlegate sandstone: 35 th U.S. Symposium on Rock Mechanics.

Prasad, M., and M. H. Manghnani, 1997, Effects of pore and differential pressure on compressional wave velocity and quality factor in Berea and Michigan sandstones: Geophysics, 62, 1163-1176, doi: 10.1190/ 1.1444217 .

Reuss, Z. A. A., 1929, Berechnung der Fliessgrenze von Mischkristallen auf grund der Plastizitätsbedingungen für Einkristalle: Zeitschrift für Angewandte Mathematik und Mechanik, 9, 49-58.

Simmons, G., and W. F. Brace, 1965, Comparison of static and dynamic measurements of compressibility of rocks: Journal of Geophysical Research, 70, 5649-5656, doi: 10.1029/JZ070i022p05649.

Teeuw, D., 1971, Prediction of formation compaction from laboratory compressibility data: SPE Journal, 11, 263-271.

Terzaghi, K., 1923, Die Beziehungen zwischen Elastizitat und Innendruck: Sitzungsberichte, Akademie der Wissenschaften, K I. IIa 132 (3-4), $105-121$.

Teufel, L. W., and N. R. Warpinski, 1990, Laboratory determination of effective stress laws for deformation and permeability of chalk: 3rd North Sea Chalk Symposium.

Tjetland, G., T. Kristiansen, and K. Buer, 2007, Reservoir management aspects of early waterflood response after 25 years of depletion in the Valhall field: International Petroleum Technology Conference.

Todd, T., and G. Simmons, 1972, Effect of pore pressure on the velocity of compressional waves in low-porosity rocks: Journal of Geophysical Research, 77, 3731-3743, doi: 10.1029/JB077i020p03731. 
Tutuncu, A. N. A. L. Podio, and M. M. Sharma, 1994, Strain amplitude and stress dependence of static moduli in sandstones and limestones in P. P. Nelson, and S. E. Laubach, eds., Rock mechanics: Models and measurements challenges from industry: Balkema, 489-496.

Tutuncu, A. N., and M. M. Sharma, 1992, Relating static and ultrasonic laboratory measurements to acoustic log measurements in tight gas sands: SPE Annual Technical Conference and Exhibition.
Voigt, W., 1910, Lehrbuch der kristallphysik: B.G. Terebner

Wang, Z., 2000, Dynamic versus static elastic properties of reservoir rocks, in Z. Wang, and A. Nur, eds., Seismic and acoustic velocities in reservoir rocks; Volume 3: Recent developments: Geophysics Reprint Series, 19, 531-539.

Yale, D. R., J. A. Nieto, and S. P. Austin, 1995, The effect of cementation on the static and dynamic mechanical properties of the Rotliegendes sandstone: 35 th U. S. Symposium on Rock Mechanics. 